\title{
The Improvement of the Technology of Winter Wheat Grain Production for the Purpose of Energy Saving
}

\author{
Gennady Georgievich Maslov, Vasily Timofeevich Tkachenko, \\ Elena Mikhaylovna Yudina, Mikhail Reminovich Kadyrov \\ and Svetlana Alekseevna Kalitko
}

The Kuban State Agrarian University, 13, Kalinina St., Krasnodar, 350044, Russia

DOI: http://dx.doi.org/10.13005/bbra/1875

(Received: 15 July 2015; accepted: 20 September 2015)

\begin{abstract}
The technological directions of energy saving in winter wheat grain production, an advanced technological set of machinery, and the structure of the components of total energy expenditure are substantiated. The purpose of the paper is to substantiate the reduction of the energy intensity of winter wheat grain production due to design and technology factors and combining operations when implementing manufacturing processes. The comparative assessment of machines and sets of machines on the energy criterion is made in a differentiated way, with regard to the individual components of total energy expenditure in the compared wheat cultivation technologies. The proposed technology ensures the improvement of the energy efficiency of grain production by 42 per cent.
\end{abstract}

Key words: Energy expenditure, energy efficiency, technology, machine-tractor units, combined harvester, the complexity of works, crop rotation.

The reduction of the cost of power supply of agricultural processes and improving the competitiveness of agricultural products have always been the focus of attention of science and industry. The problem of energy saving in the agroindustrial complex (AIC) has become especially urgent in recent years, taking into account the constant rise in the prices for fuel and lubricants, fertilizers, pesticides, and the lack of stability in the foreign exchange market.

By energy saving in the agroindustrial complex we shall mean savings in raw materials, fuel and lubricants, manpower, and funds, for the purpose of ensuring the competitiveness of agricultural products. Therefore, the task of

\footnotetext{
* To whom all correspondence should be addressed.
}

reducing the labor, material and energy costs, related to the manufacturing of these products, remains relevant. The problem of energy saving is in the focus of attention both in Russia $[1,7,16$, etc.] and abroad [2, 3, etc.].

The labor and material costs of the production of agricultural products in Russia are very high. For example, the labor input, required for the production of 1 ton of grain, amounts to 9 man hours, while in the United States - 2.6, for the production of beets, respectively, 7.5 and 1.1, for potatoes -26.5 and 2.2, for milk -85 and 4 , for beef -580 and 22 , for pork -330 and 8 man hours ${ }^{16}$. The energy intensity of agricultural products in Russia is 2-4 times higher than in the United States and other countries of the world. For the production of 1 ton of grain $178 \mathrm{~kg}$ of fuel equivalent is consumed, while in the United States - only $45 \mathrm{~kg}$. Total energy expenditure per 1 ha of farmland is respectively 280 and $121 \mathrm{~kg}$ of fuel equivalent ${ }^{8}$. Agricultural energy 
expenditure annually increases by $1.1 \%{ }^{16}$.

Taking the foregoing into consideration, the purpose of the paper is to substantiate the reduction of the energy intensity of winter wheat grain production due to design and technology factors and combining operations when implementing manufacturing processes.

The substantiation is provided for four parts of the wheat production technology: tillage and sowing; crop tending; harvesting and processing of grain; carrying out basic works of post-harvest complex.

\section{Methodology}

The analysis of the operations of the basic technology of winter wheat grain production and the synthesis of the proposed new technology solutions are implemented on the basis of our own research, the results of testing the technologies and equipment in the Krasnodar region, as well as the analysis of domestic and foreign literature [2, 3 , 10, etc.]. The calculation of the efficiency of technological operations in terms of the energy efficiency is carried out using the methodology of the All-Russia Research Institute for Mechanization of Agriculture (WIM) ${ }^{12}$. Total energy expenditure was determined for each operation of the flow process chart of winter wheat cultivation according to the basic technology (Table 1) and the proposed advanced technology (Table 2).

Table 1 presents the main operations of winter wheat cultivation according to the basic technology, as well as the set of post-harvest works (processing of grain, tillage and post-harvest sowing of mustard as green manure). All the normative indicators for the calculation are taken according to the methodology of the All-Russia Research Institute for Mechanization of Agriculture [12] and the State Research Institute for the Repair and Maintenance of Tractors and Machines (GOSNITI) [19]. The basic technology (Table 1) applies the widely used agricultural machinery, which is not always able to fully introduce modern energy-saving technologies and needs to be replaced, which was implemented in the proposed advanced winter wheat cultivation technology (Table 2).

The flow process charts show the list and sequence of all technological operations (column 2 ), agrotechnical requirements for their implementation (column 3), the configuration of the unit: the model of the tractor (column 4) and agricultural machine (column 5), the performance rate of the unit (column 6), the amount of attending personnel (column 7), the components of energy expenditure: direct (energy of the consumed fuel, column 8), materialized (energy expenditure for the production of fertilizers, pesticides, etc., column 9), human labor energy expenditure (column 10), energy expenditure for the production of tractors and machines (column 11) and total energy expenditure (column 12).

The calculation of energy expenditure takes into account materialized energy expenditure for the production of fertilizers, pesticides, etc. (column 9, Table 1). The latter have a very high level of energy expenditure compared to other technological operations, exceeding by several times even plowing as the most energy-intensive operation. In this regard, it is very important to reduce the total energy expenditure of the most energy-intensive operations ${ }^{8}$.

The materialized energy expenditure in crop production takes into account the energy expenditure for the use of fertilizers, chemicals, water, grain, etc. The energy, which is materialized in them, is included into the energy expenditure for the processing, treating, harvesting and storage of crops ${ }^{12}$. For example, according to Table 1, the energy expenditure for the production of manure (column 9) amounted to $4200 \mathrm{MJ} / \mathrm{ha}$, for the sowing of wheat $-630 \mathrm{MJ} / \mathrm{ha}$, for the application of fertilizers using an aircraft AN-2 - $1260 \mathrm{MJ} / \mathrm{ha}$. When using the basic technology, the total energy expenditure for tillage, wheat sowing, crop tending, harvesting and processing of crops amounts to 12371.79 MJ/ha. Of these, direct energy expenditure (fuel consumed) amounts to 3499.34 MJ/ha, energy expenditure for utilities and machines - 2498.96 $\mathrm{MJ} / \mathrm{ha}$, or $20.29 \%$, materialized energy expenditure - $6354 \mathrm{MJ} / \mathrm{ha}$, or 51.4\%, and human labor energy expenditure $-19.59 \mathrm{MJ} / \mathrm{ha}$, or $0.15 \%$.

The post-harvest set of works in the winter wheat cultivation technology includes the post-harvest tillage and sowing green manure to be used as fertilizer. This technique is already widely used in practice, and its effectiveness is studied in [4]. In the Kuban region, mustard is most commonly used as green manure.

The post-harvest set of works according to the 
basic technology (stubble disking and mustard sowing) requires, according to our calculations, 903.57 MJ/ha. Thus, the structure of total energy expenditure for the production of winter wheat grain according to the basic technology, including the post-harvest set of works (stubble disking and post-harvest sowing of mustard as green manure) is the following (Table 1): direct energy expenditure - 4127.34 MJ/ha, or 31.09\%; energy expenditure for utilities and machines - 2773.1 MJ/ha, or 20.9\%; materialized energy expenditure $-6354 \mathrm{MJ} / \mathrm{ha}$, or 47.9\%; human labor energy expenditure - 20.9 MJ/ ha, or $0.16 \%$, in total $-13275.4 \mathrm{MJ} / \mathrm{ha}$.

\section{RESULTS}

The basic technology of winter wheat cultivation (Table 1) includes 19 technological operations for the production of grain and nongrain part of the crop - chaff, which is used for forage. The set of basic machinery includes outdated equipment, which is still in use, but is no longer able to ensure the increase of labor efficiency, the reduction of all kinds of expenditures (energy, labor, and cash expenditures), high quality of field works and their timely implementation. The technology insufficiently uses combination of operations, energy saving in the process of fertilizing, spraying, multifunctional units. Harvesting and post-harvest processing of crops are organized inefficiently, and this problem has not been addressed up to the present moment. The use of heavy combined harvesters results in large crop losses and shattering of grain; together with cargo vehicles, combined harvesters contribute to the overconsolidation of soil, which reduces future yields. In this regard, the transition to a new energy-saving technology, which would eliminate the above-mentioned disadvantages and improve the competitiveness of grain, is an extremely relevant task.

In the proposed advanced technology (Table 2) many technological operations are significantly improved. The total amount of technological operations is reduced to 17 . The proposed set of new-generation machinery includes new tractors, tillage machines, sowers, mineral and organic fertilizer applicators, lowvolume sprayers, high-performance trailed combined harvesters, on the basis of which multifunctional units were assembled, according to our patents for inventions [6]. In the process of grain crop harvesting, along with trailed combined harvesters, grain auger wagons are to be used to transport grain from combined harvesters to the thrashing floor (if the distance is up to $3 \mathrm{~km}$ ) or to large capacity trailers (if the distance is more than $3 \mathrm{~km}$ ), like Fliegl trailers. These techniques alone will reduce the overconsolidation and dispersion of soil, losses of grain and all kinds of expenditures. The technology of unwinnowed grain harvesting is used: grain and chaff are collected into the grain tank of a combined harvester, and straw is cut and spread across the field or is left standing in case of harvesting grain by stripping (using a special adapter of a combined harvester). The unwinnowed heap of chaff and grain, which is transported to the threshing floor, is divided into pure grain and chaff - non-grain part of the crop, very valuable for livestock farming, which is stored at feeding platforms or under shelter.

To divide the unwinnowed heap into grain and chaff, the high-performance aspiration and screening separator İN230 (Canada) can be used, which has a throughput rate of $100 \mathrm{t} / \mathrm{h}$. The technology of unwinnowed grain harvesting has been developed in our country for many years by the All-Russia Research Institute for Mechanization of Agriculture (VIM), the All-Union Institute for Agricultural Machine Building (VISHOM), etc., but this technology has not become a frequent practice because of the bulkiness of the stationary processing unit. Currently the availability of the series-produced and tested MN230 separator easily solves the problem of unwinnowed grain harvesting ${ }^{2,3}$.

The proposed technology of wheat cultivation also effectively solves the problems of the transportation of seeds and fertilizers and loading grain seeders using Reboke-16 loaders, the transportation and application of manure using PUS-15 trailers, seeding using Rapid seeders (Sweden), spraying crops using high-performance self-propelled sprayers Tuman-2D ${ }^{18}$, which can also be reequipped to apply mineral fertilizers (Table 2). Additional advantages of Tuman-2D sprayers are high performance (up to 1000 ha per day) and low ground pressure of tires (no more than $100 \mathrm{~g}$ per $1 \mathrm{~cm} 2$ ), which also reduces the consolidation of soil [18]. High performance and functional 


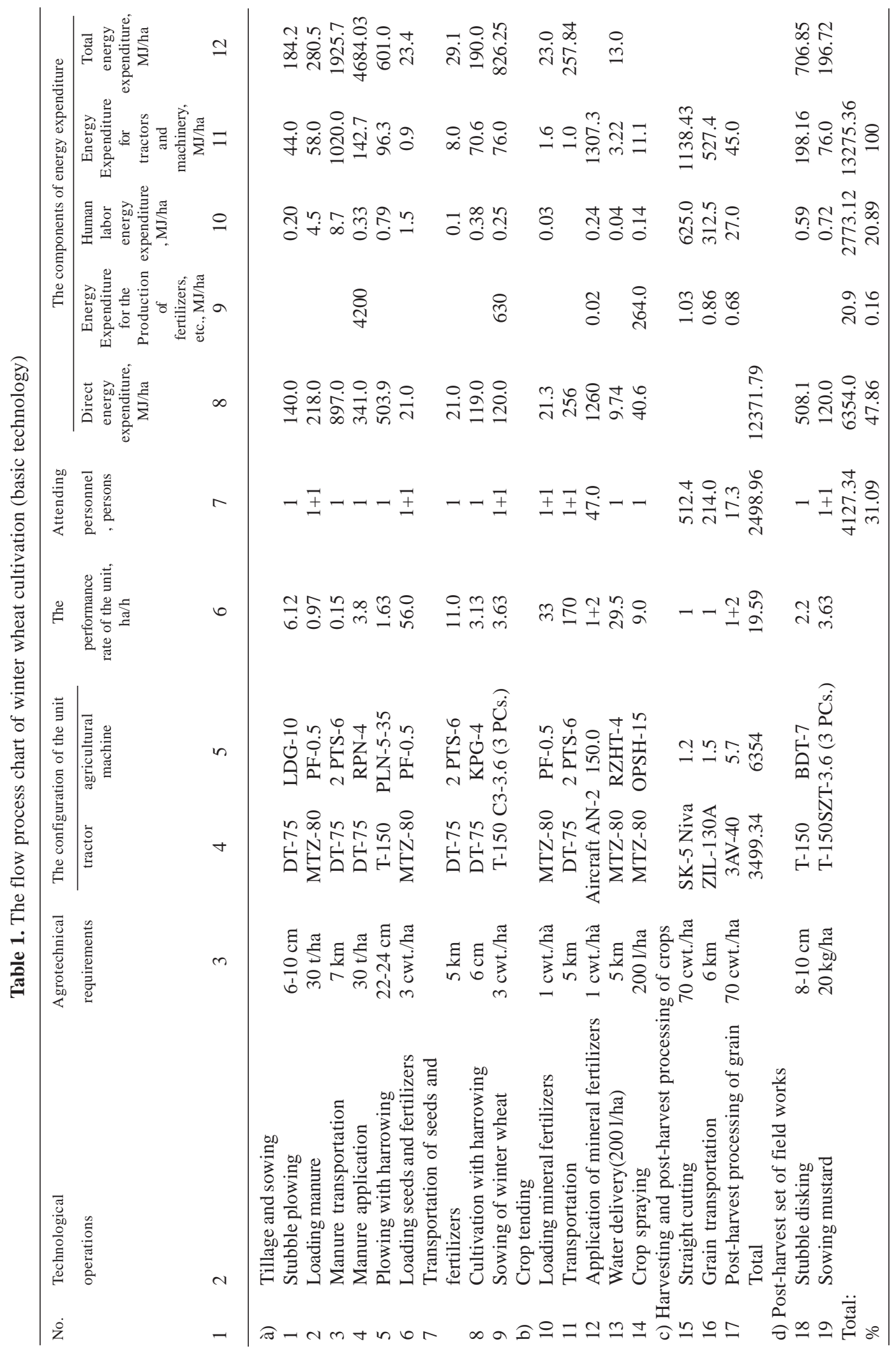




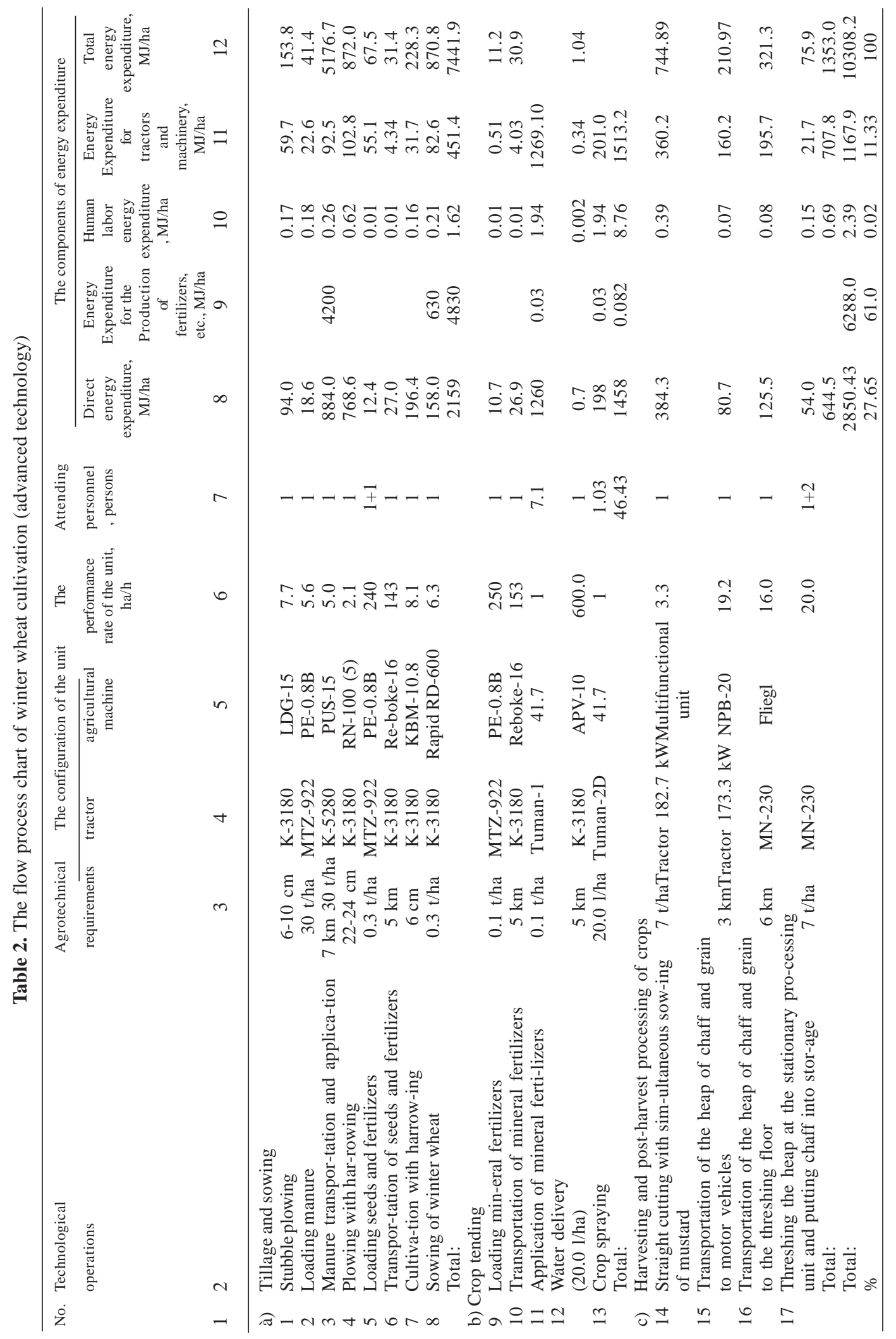


efficiency are ensured by the Norwegian swivel plows RN-100 (5) [15] and the MSC-10 cultivator MSC- $10.5^{20}$ (Yaroslavl, Russia).

All the machines, proposed in the advanced technology, successfully passed official and performance tests. They make it possible to successfully achieve the goal of the work - that is, to reduce total energy expenditure for the production of winter wheat grain. In our view, this is the preferred criterion of the comparative assessment of the basic and advanced sets of machines. Other criteria, such as minimum operating costs, maximum productivity, minimum labor requirements for the manufacturing of products, minimum fuel consumption, etc., although useful, do not address the issue systemically and do not take into account market conditions. Energy expenditure and its reduction in the agricultural sector and, in particular, in crop production, is a necessary method of the comprehensive study of the energy intensity of products and makes it possible to systemically assess the efficiency of manufacturing. Table 3 shows the total energy expenditure for the basic and advanced winter wheat cultivation technologies, and the components of energy expenditure in megajoule per 1 ha of planting acreage and also in percentage terms.

\section{DISCUSSION}

The comparison of technological sets of machinery for winter wheat cultivation should be made in a differentiated way with the calculation of the following coefficients of energy expenditure: - direct energy expenditure

$$
\mathrm{K}_{\mathrm{ED}}=\frac{\mathrm{E}_{\mathrm{DN}}}{\mathrm{E}_{\mathrm{DB}}}=\frac{2850.45}{4127.34}=0.69 ;
$$

- human labor energy expenditure

$$
\mathrm{K}_{\mathrm{EL}}=\frac{\mathrm{E}_{\mathrm{LN}}}{\mathrm{E}_{\mathrm{LB}}}=\frac{2.39}{20.9}=0.12 ;
$$

- energy expenditure for the production of mechanical equipment

$$
\mathrm{K}_{\mathrm{EM}}=\frac{\mathrm{E}_{\mathrm{MN}}}{\mathrm{E}_{\mathrm{NB}}}=\frac{1167.9}{2773.12}=0.42 \text {; }
$$


- total energy expenditure

$$
\mathrm{K}_{\mathrm{E}}=\frac{2850.45+2.39+1167.9}{4127.34+20.9+2773.12}=\frac{4020.74}{6921.36}=0.58 \text {; }
$$

where $\mathrm{K}_{\mathrm{ED}}$ is the coefficient of direct energy expenditure; $E_{D N}$ and $E_{D B}$ are, respectively, direct energy expenditure for new and basic technologies, MJ/ha;

$\mathrm{K}_{\mathrm{EL}}$ is the coefficient of human labor energy expenditure; $\mathrm{E}_{\mathrm{LN}}$ and $\mathrm{E}_{\mathrm{LB}}$ are, respectively, human labor energy expenditure for new and basic technologies, MJ/ha;

$\mathrm{K}_{\mathrm{EM}}$ is the coefficient of energy expenditure for the production of mechanical equipment; $\mathrm{E}_{\mathrm{MN}}$ and $\mathrm{E}_{\mathrm{MB}}$ are, respectively, energy expenditure for the production of mechanical equipment for new and basic technologies, $\mathrm{MJ} /$ ha; expenditure.

$\mathrm{K}_{\mathrm{E}}$ is the coefficient of energy

Thus, the advanced technological set of machines makes it possible to improve the efficiency of winter wheat cultivation technology by $31 \%$ in terms of direct energy expenditure, by $88 \%$ in terms of human labor energy expenditure, by $58 \%$ in terms of the energy expenditure for the production of mechanical equipment, and to improve the overall efficiency by $42 \%$.

A well-known methodology of the AllRussia Research Institute for Mechanization of Agriculture $^{12}$, according to which our calculations were made, does not make it possible to make accurate assessment of the overall effectiveness of the advanced technology on the coefficient of total energy expenditure $\mathrm{K}_{\mathrm{E}}$. We propose to call this coefficient "the level of energy saving of the advanced technology" $L_{E}$ and define it according to the formula ${ }^{5}$ :

$$
\mathrm{L}_{\mathrm{E}}=\left(1-\mathrm{K}_{\mathrm{E}}\right) \cdot 100=(1-0.58) \cdot 100=42 \% \text {, }
$$

where $L_{E}$ is the level of energy saving of the advanced technology, \%.

Thus, $\mathrm{L}_{\mathrm{E}}$ makes it possible to immediately answer the question, by how much percent the total energy expenditure for grain production is reduced in case of introducing the advanced technology. In our example it is reduced by $42 \%$.

To improve the performance and quality of operation, reduce labor and cash expenditures, and improve working conditions, manufacturing processes are constantly improved during designing by fundamental changes of the process itself, improving the design and the reliability of the machines, using integrated and multi-purpose units, reducing the number of passes of heavy machinery, etc.

For example, the technology of cultivation of grain crops provides for many operations, related to the movement of tractors and machines across the field and adversely affecting the soil, wherein all the operations (plowing, fertilizing, pre-sowing cultivation, harrowing, leveling and packing of the surface, sowing) are, as a rule, carried out separately (Table 1). As a result, a lot of labor and energy is consumed, and, more importantly, the repeated impact of tractor units on the soil results in the deteriorating of the soil structure and reduced fertility.

Therefore, for the purpose of the minimization of tillage it is important to create and use combined units, carrying out several operations simultaneously (in one pass), and also to apply soil herbicides, boardless plowing, etc. The units were created, that perform simultaneously five technological operations: application of mineral fertilizers, loosening of the plow layer, leveling and packing of the soil, sowing of grain. There are also units, combining operations only in the process of preplanting tillage cultivation, leveling and packing of the soil ${ }^{20}$, harvesting ${ }^{9}$, or grain harvesting and tillage $\mathrm{e}^{14,21}$.

The industrialization of agriculture resulted in the growing consumption of energy and chemicals, on the one hand, and on the other hand - in greater soil erosion and contamination of the agricultural products. The costs of energy and nature protection in agriculture are constantly increasing, therefore, the improvement of the crop cultivation technology for the purpose of the reduction of these costs needs further scientific research.

In the developed countries, farming is developing in the direction of searching new techniques of organic agriculture and the expansion of human knowledge about transformations and transfer of nutrients and water in artificial associations. This will contribute to: 1) minimal tillage; 2) improved energy efficiency; 3) the reduction of water losses and soil erosion caused 
by irrigation; 4) the reduction of the consumption of fertilizers and improving their efficiency; 5) the use of crop residues and stubble for mulching of soil; 6) increasing the number of crops in the rotation; 7) the reduction of the use of pesticides (especially broad-spectrum pesticides); 8) introducing permanent crops, primarily legumes, into crop rotation; 9) breeding plant varieties, designed for the maximum utilization of the resources of certain areas; 10) the improvement of soil fertility and the reduction of the chemical contamination of soil (Belyuchenko, 1996).

In other words, environmental protection technologies will bring agricultural landscapes closer to natural systems and separate them from industrial cities and enclaves, therefore, agricultural systems will be more harmonically integrated in the structure of the overall landscape of local and regional ecosystems. All this will contribute to the reduction of the energy expenditure for agricultural production (Belyuchenko, 1996).

In this paper, we have already noted that simple saturation of soil with mineral fertilizers, as well as the use of chemicals for crop protection, on the one hand, don't pay off, and on the other hand, are harmful for the environment. Therefore, a balanced biologized farming system is needed, which should become the basis of maintaining fertility and high productivity of soil. The introduction of biologized farming systems on a landscape basis makes it possible to maintain the fertility of intensely used chernozems in crop rotations within three years after the plowing of the sod layer, composed of perennial legumes, due to the presence of nitrogen, accumulated by alfalfa in soil, to restore soil structure and the optimal water-air regime of active root habitable layer ${ }^{11}$. The proportion of perennial legumes in plain agricultural landscape shall be $17.4 \%$, and in the lowland $-28-33 \%{ }^{11}$. All of the above will contribute to energy saving in crop production.

An important reserve of energy saving is also a scientifically founded system of machinery for the mechanization of crop production. A set of technical facilities in the system should first of all be considered from the point of view of direct energy saving (the reduction of fuel consumption). For example, the domestically produced plow PSK4-8 considerably reduces fuel consumption in the process of plowing, as compared to the counterparts, including the foreign ones. According to the research [24], the abovementioned plow PSK-4-8 ensures saving of 10-15\% of diesel fuel, or direct energy expenditure, in the process of plowing. The same relates to the grain seeder Rapid (Sweden) and the sprayer Tuman$2 \mathrm{D}^{18}$, additionally equipped with an innovative device for the application of mineral fertilizers.

Therefore, the search for alternative less energy-intensive and soil- protecting technologies, in combination with moldboard plowing, nonmoldboard cultivation, zero tillage, and direct seeding, undoubtedly, contribute to the reduction of total energy expenditure. The optimization of the above-mentioned biologized farming system in terms of energy expenditure, and, of course, with regard to the productivity of the land, is also very important.

For example, in the above-mentioned paper $^{11}$, the structure of the methods of soil cultivation in percent of the crop rotation area of the Krasnodar region is provided for the system of primary soil cultivation. For example, moldboard plowing should account for $54 \%$ in the crop rotation of the steppe plain agricultural landscape, boardless plowing with chiseling $-19 \%$, surface cultivation $-18 \%$ and zero tillage $-9 \%$. To maintain soil fertility in this system, it is necessary to apply shredded straw of spiked cereals ( $2.5 \mathrm{t} / \mathrm{ha})+$ manure (9t/ha) $)^{11}$.

Let us build a mathematical model of the above-mentioned system of primary soil cultivation in the steppe plain agricultural landscape, using the minimum total energy expenditure for all cultivation processes as an optimization criterion.

$$
\sum_{i=1}^{I} \sum_{j=1}^{J} \sum_{z=1}^{z} \mathrm{E}_{i j} \cdot \delta_{i j z} \cdot F \rightarrow \min ,
$$

where $\mathrm{E}_{\mathrm{ijz}} \mathrm{E}_{i j z}$ is the total energy expenditure for the soil cultivation by the i-th unit, using the j-th method of cultivation, for the to z-th operation;

$\delta_{\mathrm{ijz}}$ is the share of the soil area (in \%), cultivated by the i-th unit, using the j-th method of cultivation, for the z-th operation (according to the recommendations of [11, p. 128]);

$F$ is the total area of arable land in the steppe plain agricultural landscape, ha.

On the basis of the minimum value of the 
optimization criterion (minimum total energy expenditure for all z-th technological operations), the composition of the i-th unit (tractor and machine) and the $\mathrm{j}$-th method of cultivation for each z-th operation are substantiated.

\section{CONCLUSIONS}

Given the high level of energy saving $\left(\mathrm{L}_{\mathrm{E}}\right)$ in the proposed technology, which amounts to $42 \%$, it is possible to suggest ways of further reducing the total energy expenditure for grain production. According to Table 3, in terms of the components of the total energy expenditure, the energy expenditure for the production of fertilizers, pesticides, etc. accounts for the largest share of the total energy expenditure for the production of grain. For example, in the basic technology, this proportion is $47.86 \%$ of the total energy expenditure per 1 ha of wheat planting acreage, while in the advanced technology - 61\%, though the level of energy expenditure for this component in the advanced technology (6288 MJ/ha) is slightly lower than that of the basic technology (6354 MJ/ha).

The level of human labor energy expenditure reduces almost 9 times: for the basic technology it amounts to $20.9 \mathrm{MJ} / \mathrm{ha}$, while for the advanced technology $-2.39 \mathrm{MJ} / \mathrm{ha}$. The energy expenditure for the production of mechanical equipment is reduced almost 2 times in the advanced technology: $1167.9 \mathrm{MJ} / \mathrm{ha}$ in the advanced technology and 2773.12 MJ/ha in the basic technology.

The reduction of the energy expenditure for the production of fertilizers, pesticides, etc. can be achieved in the near future by using the latest biotechnologies (humification agents and Rizobakt $)^{13}$. The improvement of the quality of grain $^{17}$ is also very important, and it depends on the technology of cultivation (the best varieties, the best predecessors of wheat, harvesting in a short period of time (no longer than 5 days), the newest equipment, etc. ${ }^{9}$ ). Thus, the extensive use of the latest achievements of agricultural technology for plant protection ${ }^{23}$, soil cultivation ${ }^{11}$, operation of equipment ${ }^{16}$ create reliable prerequisites for further reduction of the energy intensity of crop production. The directions of our further research include the study of the consistent patterns of qualitative indicators and the preservation of harvested grain depending on the design features of modern and advanced threshing units.

The level of energy saving for the proposed winter wheat cultivation technology amounted to $42 \%$, as compared to the basic technology, and the specific total energy expenditure per one ton of grain amounted to, respectively, $1896.5 \mathrm{MJ} / \mathrm{t}$ and $1472.6 \mathrm{MJ} / \mathrm{t}$.

\section{REFERENCES}

1. Borodin, I.F., The Prospects of Energy Saving in Russian Agricultural Sector. In Scientific and Technological Progress in the Engineering Sphere of the Agroindustrial Sector of Russia. Moscow: GOSNITI, 1995; 54-61.

2. Heidebrecht, I. P., Canadian Crop Harvesting Technology. Agricultural Machinery and Equipment, 2006; 4: 38-40.

3. Gol2 tyapin, V.Ya., Foreign Complex of Machines for Harvesting Crops with the Processing of the Unwinnowed Heap of Chaff and Grain at the Stationary Thresher. Tractors and Agricultural Machinery, 2008; 5: 51-52.

4. Kashbulgayakov, P., Green Manure Improves Yields. Selskiy Mechanizator, 2006; 3: 18-19.

5. Klenin, N.I and A.A. Zolotov, Calculation of Harvesting and Transportation Complex: Guidelines. Moscow: FSEI HPO "Moscow State Agroengineering University”, 2003.

6. Maslov, G.G., A.V. Palapin and O.S. Marchenko, Combined Unit for Harvesting and Simultaneous Sowing of Agricultural Crops. Patent RF No. 249181; 2013.

7. Kormanovskiy, L.P., The Paths of Development of the Main Directions of Scientific and Technical Policy in Agricultural Sector and Improvement of Technical Level of Machines. In Scientific and Technological Progress in the Engineering Sphere of the Agroindustrial Sector of Russia (Proceedings of the Scientific and Technological Conference, October 15-16, 1996). Moscow: All-Russia Research Institute for Mechanization of Agriculture, 1997.

8. Kormanovskiy, L.P., Energy Saving is a Priority Task in the Coming Century. Agricultural Machinery, 1999; 4: 3-6.

9. The Concept of the Development of Mechanization of Harvesting Grain Crops for the Period up to 2005, 1994. Moscow: AllRussia Research Institute for Mechanization of Agriculture.

10. Lipkovich, E.I., The Technology of Grain Crops 
Harvesting Technology with Combination of After Harvesting Operations. Tractors and Agricultural Machinery, 2010; 12: 48-50.

11. Malyuga, N.G. et al., Balanced Biologized Farming System is the Basis of Maintaining Soil Fertility and High Productivity of Kuban Chernozems. Proceedings of the Kuban State Agrarian University, 2015; 1(52): 125-128.

12. Methodical Recommendations on the Fuel and Energy Evaluation of Agricultural Machinery, Manufacturing Processes and Technologies in Crop Production, Moscow: All-Russia Research Institute for Mechanization of Agriculture, 1989.

13. LLC “Saint-Petersburg Technologies”, We will Help You to Grow and Preserve Crops! Modern Farmer, 2014; 6-7: 28.

14. Palapin, A.V., Comprehensive Analysis of the Technical Level of Combined Harvesters. Agricultural Machinery and Technologies, 2013; 6: 26-28.

15. Kverneland Kleep, A Newsletter, 1992.

16. Chernoivanov, V.I., A.E. Severnyy et al. Efficient Use of Resources in the Process of Operation of Agricultural Machinery. Moscow: GOSNITI FSSI “Rosinformagrotech”, 1992.

17. Russian Grain is in Little Demand in the World Market, Chief agronomist, 2009; 11: 6.
18. LLC “Torgovyy Dom Agrotekhnik”, SelfPropelled Sprayer-Spreader Tuman-2D, 2014.

19. The Reference Book of Standard Materials on Works Implemented by Machine and Technological Stations, Moscow: FSSI "Rosinformagrotech", 2001.

20. Login A.D. (Ed.), Modern Technologies and Methods of the Mechanization of Tillage, Seeding, Planting, Fertilizer Treatment and Plant Protection. Novosibirsk: Novosibirsk State Agrarian University, 2001.

21. Burdun, A. et al., A Method and Apparatus for Cultivating Agricultural Crops. Patent RF No. 2421978 C2, 2011.

22. Tikhomirov, A.B., Challenges and Promising Directions of Energy Saving in Agricultural Sector. In Scientific and Technological Progress in the Engineering Sphere of the Agroindustrial Sector of Russia. Moscow: GOSNITI, 1997; 117-124.

23. Chulkina, V.A., E.Yu. Toropova, Yu.I. Chulkin and G.Ya. Stetsov, Agrotechnical Method of Plant Protection. Moscow: IVC Marketing: UKEA, 2000.

24. Energy-Efficient High-Speed PSK Plows. Research and Production Company "SUR". Date Views 17.09.2015 http://www.sur-psk.ru. 